\title{
Modulation of cell growth and cisplatin sensitivity by membrane $\gamma$-glutamyltransferase in melanoma cells
}

\author{
Maria Franzini ${ }^{a}$, Alessandro Corti ${ }^{a}$, Evelina Lorenzini ${ }^{a}$, Aldo Paolicchi ${ }^{a}$, \\ Alfonso Pompella ${ }^{a}$, Michelandrea De Cesare ${ }^{b}$, Paola Perego ${ }^{b}$, Laura Gatti ${ }^{b}$, \\ Roberto Leone ${ }^{c}$, Pietro Apostoli ${ }^{d}$, Franco Zunino, ${ }^{b, *}$

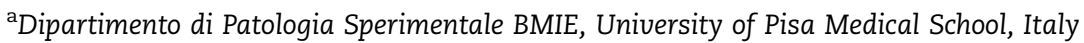 \\ ${ }^{\mathrm{b}}$ Istituto Nazionale Tumouri, via Venezian 1, 20133 Milan, Italy \\ cIstituto di Farmacologia, Università di Verona, 37124 Verona, Italy

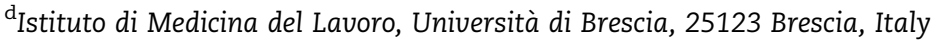

\section{A R T I C L E I N F O}

\section{Article history:}

Received 17 February 2006

Received in revised form

31 March 2006

Accepted 7 April 2006

Available online 22 August 2006

\section{Keywords:}

$\gamma$-Glutamyltransferase

Glutathione

Cysteine

Cisplatin

Drug resistance

Melanoma

\begin{abstract}
A B S T R A C T
The plasma membrane enzyme $\gamma$-glutamyltransferase (GGT) is regarded as critical for the maintenance of intracellular levels of glutathione (GSH). GGT expression has been implicated in drug resistance through elevation of intracellular GSH. The dependence of intracellular GSH on GGT expression was not conclusively ascertained. The present study was designed to investigate the role of GGT and of intracellular GSH levels in modulating proliferation and sensitivity to cisplatin of melanoma cells. GGT transfection resulted in increased growth, both in vitro and in tumour xenografts. In addition, GGT-transfected cells exhibited reduced sensitivity to cisplatin associated with lower DNA platination. A decrease in intracellular GSH levels, rather than an increase, was observed in GGT-transfected cells; moreover, in cysteine-deficient conditions, the expression of GGT did not provide transfected cells with the ability of utilising extracellular GSH. In conclusion, these results indicate that GGT activity confers a growth advantage unrelated with intracellular glutathione supply, and are consistent with the interpretation that cisplatin resistance is the consequence of modifications of cellular pharmacokinetics as a result of extracellular drug inactivation by thiol metabolites originated by GGT-mediated GSH cleavage.
\end{abstract}

(c) 2006 Elsevier Ltd. All rights reserved.

\section{Introduction}

Gamma-glutamyltransferase (GGT) is a cell membrane enzyme endowed with the unique capability of initiating the hydrolysis of extracellular glutathione (GSH, $\gamma$-Glu-Cys-Gly), thus potentially providing GGT-positive cells with a secondary source of cysteine. ${ }^{1}$ GGT activity is frequently elevated in human cancers, ${ }^{2}$ and most cultured cancer cell lines display elevated GGT activity, which suggests a role for this enzyme in conferring survival and growth advantages. ${ }^{3}$ Since intracellular GSH synthesis in vivo is limited by the availability of cys- teine, ${ }^{4}$ it has been speculated that GGT activity would provide cancer cells with a selective advantage as compared to normal tissues, ${ }^{5}$ by enhancing their availability of cysteine. Accordingly, transfection of murine fibroblasts with GGT cDNA provides them with the ability to use extracellular GSH as a source of cysteine. ${ }^{6,7}$ Adequate supplies of cysteine are required for protein synthesis, as well as synthesis of GSH itself, which is involved in critical detoxifying and antioxidant defences of the cell. Intracellular GSH is in fact involved in the resistance of cancer cells to antitumour agents, e.g. platinum-based drugs. The increase of GGT expression and of

* Corresponding author: Tel.: +39 2 23902267; fax: +39 223902692.

E-mail address: franco.zunino@istitutotumori.mi.it (F. Zunino). 0959-8049/\$ - see front matter @ 2006 Elsevier Ltd. All rights reserved. doi:10.1016/j.ejca.2006.04.016 
intracellular GSH was shown to accompany the acquisition of cell resistance to cisplatin ${ }^{8}$ (CDDP), while the depletion of cellular GSH can sensitise resistant cells to CDDP toxic action. ${ }^{9}$ Hanigan et al. $^{10}$ observed that inhibition of GGT enhanced the antitumour effect of cisplatin in tumour xenografts in vivo.

Nevertheless, direct evidence that GGT overexpression supports cancer cell growth and drug resistance by increasing intracellular GSH has never been provided. On the contrary, (i) several authors reported a decrease of intracellular GSH after transfection with GGT cDNA; ${ }^{11-13}$ (ii) no variation, or even a decrease, in intracellular GSH levels of xenotransplants obtained in nude mice using GGT-transfected tumour cells was reported, ${ }^{10,14}$ and (iii) CDDP-resistant melanoma clones expressing increased GGT activity exhibited significantly lower intracellular GSH levels, as compared to GGT-negative clones derived from the same tumour metastasis. ${ }^{15,16}$

In contrast, there is evidence that important GGT-mediated reactions occur in the extracellular microenvironment, where the production of the thiol metabolite cysteinyl-glycine has been documented to promote prooxidant reactions. ${ }^{17} \mathrm{We}$ have recently shown that production of cysteinyl-glycine can represent an extracellular line of defence against CDDP cytotoxicity. ${ }^{18,19}$ In the present study, we show that the transfection of melanoma cells with GGT cDNA resulted in reduced sensitivity to cisplatin but did not improve their ability to maintain their GSH stores when cultured at limiting cysteine concentrations. The CDDP-resistance of GGT-transfected cells was consistent with a reduced extent of DNA platination in GGT-transfected cells, which could not be ascribed to drug inactivation by intracellular GSH.

\section{Materials and methods}

\subsection{Chemicals}

Unless otherwise indicated, all reagents were from Sigma Chemical Co. (Milan, Italy).

\subsection{Cell lines, culture conditions and transfections}

Melanoma cell clones, obtained from a subcutaneous human metastasis (Me 665/2), were kindly provided by Dr. G. Parmiani (Istituto Nazionale Tumori, Milan, Italy). The c21 clone, possessing only traces of GGT activity, was used for the present study. In c21 cells, GGT activity was increased by stable transfection with a vector (pcDNA3, Invitrogen) containing the full-length cDNA of human GGT. ${ }^{20}$ A lipid-based transfection protocol (Lipotaxi mammalian transfection kit, Stratagene) was used. Of the several subclones thus generated, one presenting high GGT activity (c21/GGT) and one in which no increase of GGT activity was observed (c21/basal) were chosen. Cells were routinely grown in RPMI 1640 medium, supplemented with $5 \%(\mathrm{v} / \mathrm{v})$ heat-inactivated foetal calf serum, $2 \mathrm{mM}$ L-glutamine (L-Gln) and $0.5 \mathrm{mg} / \mathrm{ml} \mathrm{G418} \mathrm{(Gibco),} \mathrm{under}$ water-saturated atmosphere with $5 \% \mathrm{CO}_{2}$, at $37^{\circ} \mathrm{C}$.

\subsection{Determination of cell membrane GGT activity}

For preparation of cell membrane fractions, confluent cell monolayers were harvested with hypotonic lysis buffer
(10 mM Tris-HCl, $\mathrm{pH}$ 7.8). It was ascertained in preliminary determinations that the levels of GGT activity did not change after reaching confluence. Harvested cells were disrupted by a tight-fitting glass-glass Dounce homogeniser (30 strokes). Crude homogenates were centrifuged at $400 \mathrm{~g}$ for $10 \mathrm{~min}$, and then at $100,000 \mathrm{~g}$ for $60 \mathrm{~min}$, at $4{ }^{\circ} \mathrm{C}$. The resulting pellet, containing cell membranes, was resuspended in hypotonic buffer. Determination of GGT activity was performed according to Huseby and Strømme ${ }^{21}$ using $\gamma$-glutamyl- $p$-nitroanilide as a substrate and glycyl-glycine as a transpeptidation acceptor. The amounts of $p$-nitroaniline formed were measured by reading the absorbance at $405 \mathrm{~nm}$ and using a molar extinction coefficient of $9200 \mathrm{~L} / \mathrm{mol} \mathrm{cm}$. One unit of GGT activity was defined as $1 \mu \mathrm{mol}$ of substrate transformed $/ \mathrm{ml} / \mathrm{min}$. The results were expressed as $\mathrm{mU} / \mathrm{mg}$ protein.

\subsection{Determination of intracellular GSH and GSSG}

Total and oxidised glutathione were assayed by an enzymatic recycling procedure based on GSH-reductase, adapted to the microplate reader. ${ }^{22}$ Acid precipitation of cultured cells or tissue specimens was obtained with suitable volumes of $1 \%$ sulphosalicylic acid (SSA), and protein precipitates were resuspended in $0.1 \mathrm{~N} \mathrm{NaOH}$. The increase of absorbance at $405 \mathrm{~nm}$ was monitored using the microplate reader Labsystem Multiskan Plus MKII (Labsystem, Milan, Italy). GSH content was estimated by subtracting GSSG from total glutathione value. The results were expressed as nmol equivalents of GSH/mg protein in the original sample.

\subsection{Determination of soluble thiols in cell culture supernatants}

Low molecular weight thiols were determined by HPLC as described. ${ }^{23}$ Aliquots of culture supernatants were diluted twice in $0.2 \mathrm{M}$ Tris- $\mathrm{HCl}, \mathrm{pH} 8.2$, containing $20 \mathrm{mM}$ EDTA and 1\% SDS, and reduction of thiols was performed by adding tris(2-carboxyethyl)-phosphine hydrochloride (5 g/L; Molecular Probes, Invitrogen). Thiol derivatisation was then obtained by adding the fluorogenic reagent 7-fluorobenzofurazan-4-sulphonic acid ammonium salt (SBD-F, 1 g/L; Fluka). Reverse phase HPLC analysis was performed with a Beckman System Gold apparatus equipped with a RF-551 Shimadzu spectrofluorimetric detector (ex: $385 \mathrm{~nm}$, em: $515 \mathrm{~nm}$ ). SBD-F derivatised thiols were separated on a Resolve $\mathrm{C} 18$ column (Waters), using 5\% methanol in $0.2 \mathrm{M} \mathrm{KH}_{2} \mathrm{PO}_{4}, \mathrm{pH} 2.7$, as mobile phase (flow rate: $1 \mathrm{ml} / \mathrm{min}$ ).

\subsection{Cell growth at limiting cysteine concentration}

Cells were seeded in 24-well plates (10,000 cells/well) in $0.5 \mathrm{ml}$ of routine medium. After $24 \mathrm{~h}$ of growth, the medium was replaced with sulphur-aminoacids free (SAF) RPMI 1640 medium, supplemented with L-Met, $1 \%$ serum and various cysteine concentrations. Control incubations were carried out in standard RPMI 1640 medium, which contains $400 \mu \mathrm{M}$ cysteine equivalents, $3.25 \mu \mathrm{M} \mathrm{GSH}, 100 \mu \mathrm{M}$ L-Met, and 1\% serum. Cultures were grown up to $48 \mathrm{~h}$, with one medium change at $24 \mathrm{~h}$. Triplicate wells were assayed for cell viability daily for each point. The latter was assayed by means of the WST-1 reagent (Roche) according to the manufacturer's protocol. The concentration 
of the formazan produced was measured at $450 \mathrm{~nm}$ using a multilabel counter (Wallac 1420-Victor ${ }^{3}$, Perkin-Elmer).

\subsection{In vivo studies}

Experiments were carried out using 9-weeks-old female athymic Swiss nude mice (Charles River, Calco, Italy). Mice were kept in laminar flow rooms at constant temperature and humidity with free access to food and water. Experimental protocols were approved by the Ethics Committee for Animal Experimentation of the Istituto Nazionale Tumori of Milan according to institutional guidelines. At day 0 , exponentially growing melanoma cells were subcutaneously (s.c.) injected on the right flank $\left(9 \times 10^{6}\right.$ cells/mouse) suspended in $0.2 \mathrm{ml}$ of saline. Mice were inspected daily to establish the take and the time of tumour appearance. Tumour growth was followed by biweekly measurements of tumour diameters with a Vernier caliper. Tumour volume (TV) was calculated according to the formula: TV $\left(\mathrm{mm}^{3}\right)=d^{2} \times D / 2$, where $d$ and $D$ are the shortest and the longest diameter, respectively. The tumourigenicity of the two cell lines was assessed by tumour take, i.e. the ratio between the number of the growing tumours and that of the cell-injected mice.

At day 26 after cell injection, mice were sacrificed by cervical dislocation, tumours were removed and weighed. Tissue specimens were homogenised in 10 volumes of 5\% trichloroacetic acid with an Ultraturrax homogeniser (IKA-Labortechnik). Homogenates were incubated $30 \mathrm{~min}$ on ice and then centrifuged at $5000 \mathrm{~g}\left(10 \mathrm{~min}, 4^{\circ} \mathrm{C}\right)$. Supernatants were used for the determination of intracellular glutathione. Expression of GGT was verified by histochemistry, in acetone-postfixed cryostat sections ( $4 \mu \mathrm{m}$ thickness), using $\gamma$-glutamyl-4-methoxy-2-naphthylamide as a substrate and Fast Garnet GBC, as described. ${ }^{19}$

\subsection{Cell sensitivity to CDDP}

Cell sensitivity to CDDP was investigated using two incubation media: (i) standard RPMI 1640 medium, and (ii) SAF medium to which $10 \mu \mathrm{M}$ cysteine and $30 \mu \mathrm{M}$ reduced glutathione were added. Cells were plated at 4000 cells/well in 96-well plates. After $24 \mathrm{~h}$, incubation media as above were substituted and cell growth was allowed for an additional $24 \mathrm{~h}$. Aliquots of a CDDP stock solution prepared in PBS were added to the media for $24 \mathrm{~h}$. Cell viability was then determined immediately after CDDP exposure by WST-1 assay. The results are expressed as percentage of control.

\subsection{DNA platination}

DNA platination was measured as previously described. ${ }^{24}$ Cells were seeded in T-75 flasks and $48 \mathrm{~h}$ later they were exposed to cisplatin for $1 \mathrm{~h}$. DNA was extracted according to standard procedures. Platinum content was measured by inductively coupled plasma mass spectroscopy.

\subsection{Other determinations}

Protein content was determined by the method of Bradford ${ }^{25}$ using the Bio-Rad protein assay reagent and bovine serum albumin as standard. Statistical analysis of the data was assessed by ANOVA with Bonferroni test for multiple comparison, or Student's $t$ test (in vivo studies). The results are reported as means \pm SD of three or more experiments.

\section{Results}

3.1. GGT activity and cell growth at limiting cysteine concentrations

The c21 melanoma clone used for transfection experiments possessed a GGT activity of $5.36 \pm 3.80 \mathrm{mU} / \mathrm{mg}$ protein (mean $\pm \mathrm{SD}$ ). After transfection of GGT cDNA, two clones were selected, one presenting no significant variation in GGT activity (c21/basal cells: $2.35 \pm 0.29 \mathrm{mU} / \mathrm{mg}$ protein), and another in which a strong activity was induced (c21/ GGT cells: $138.23 \pm 9.11 \mathrm{mU} / \mathrm{mg}$ protein). To evaluate the role of GGT expression in the utilisation of extracellular thiols and growth rates of c21/basal and c21/GGT cells, these were studied in SAF medium. In the latter, containing the physiological concentration of GSH $(3 \mu \mathrm{M})$, increasing concentrations of cysteine were added. Under these experimental conditions, a significantly higher growth rate was observed in c21/GGT cells in all conditions tested (Fig. 1), except for the lowest cysteine concentration $(10 \mu \mathrm{M})$, at which growth of c21/GGT cells was inhibited. However, such inhibition could be reversed by supplementation with $30 \mu \mathrm{M}$ GSH (Fig. 1B).

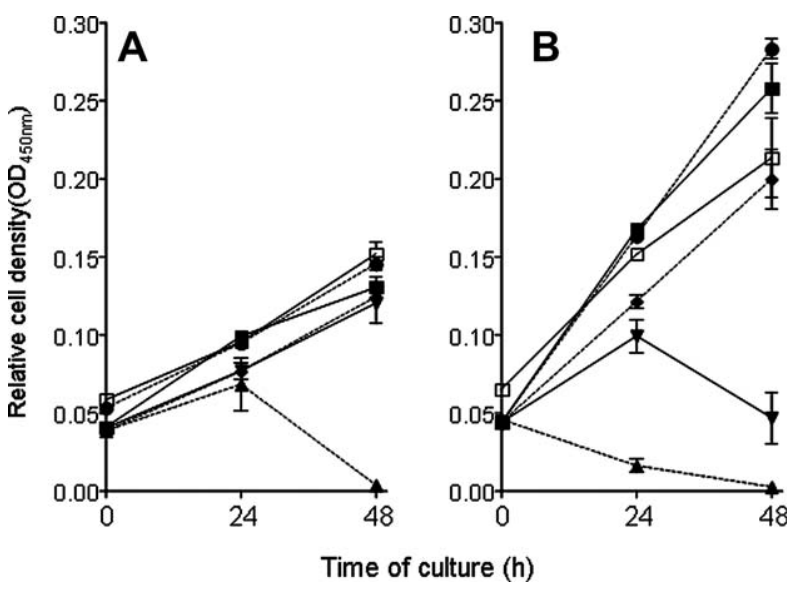

Fig. 1 - Growth of c21/basal (A) and c21/GGT (B) cells at limiting cysteine concentrations. After $24 \mathrm{~h}$ of culture, standard RPMI 1640 medium was replaced with sulphur aminoacids free (SAF) medium, containing GSH $3 \mu \mathrm{M}$ and supplemented with the following cysteine concentrations $(\mu \mathrm{M})$ : 0 ( $(\Delta) ; 10(\nabla) ; 30(\$) ; 200(0) ; 400(\square)$. Additional incubations were performed in SAF medium containing $10 \mu \mathrm{M}$ cysteine and $30 \mu \mathrm{M}$ GSH together $(\square)$. The number of live cells was estimated by WST-1 assay at the indicated time points. Results are expressed as the variation of absorbance during the first $60 \mathrm{~min}$ from WST-1 addition. Data shown are means \pm SD of three separate determinations. 


\subsection{Cell growth and glutathione content in vivo}

The ability of transfected cell lines to grow in vivo and to utilise extracellular thiols was further investigated after transplantation in nude mice, i.e. in conditions of physiologically low cysteine availability. As judged from tumour volume (Fig. 2) and weight (Table 1), growth of c21/GGT cells in vivo was higher than that of c21/basal cells. The difference in tumour volume was significant at the end of the experiment $(P<0.01)$. Histochemical analysis confirmed that tumours derived from c21/GGT cells possessed high GGT activity, both at cytoplasmic and cell membrane level (Fig. 3). GSH levels were significantly lower in tumours originated by c21/GGT cells (Table 1).

\subsection{Cell sensitivity to CDDP}

The antiproliferative effects of CDDP were assayed in standard RPMI 1640 medium as well as, for comparison, in modified SAF medium containing $10 \mu \mathrm{M}$ cysteine. SAF medium also included $30 \mu \mathrm{M} G S H$, to verify its possible utilisation by GGT-expressing cells. The sensitivity of melanoma clones to CDDP was examined using the WST-1 assay after $24 \mathrm{~h}$ drug exposure. Under such experimental conditions (Fig. 4A and B), c21/GGT cells were significantly more resistant than c21/ basal cells in both incubation conditions. In SAF-incubated cells, the difference was more marked, with an IC $_{50}$ value of c21/GGT cells approximately five times higher than that of c21/basal cells (Fig. 4B).

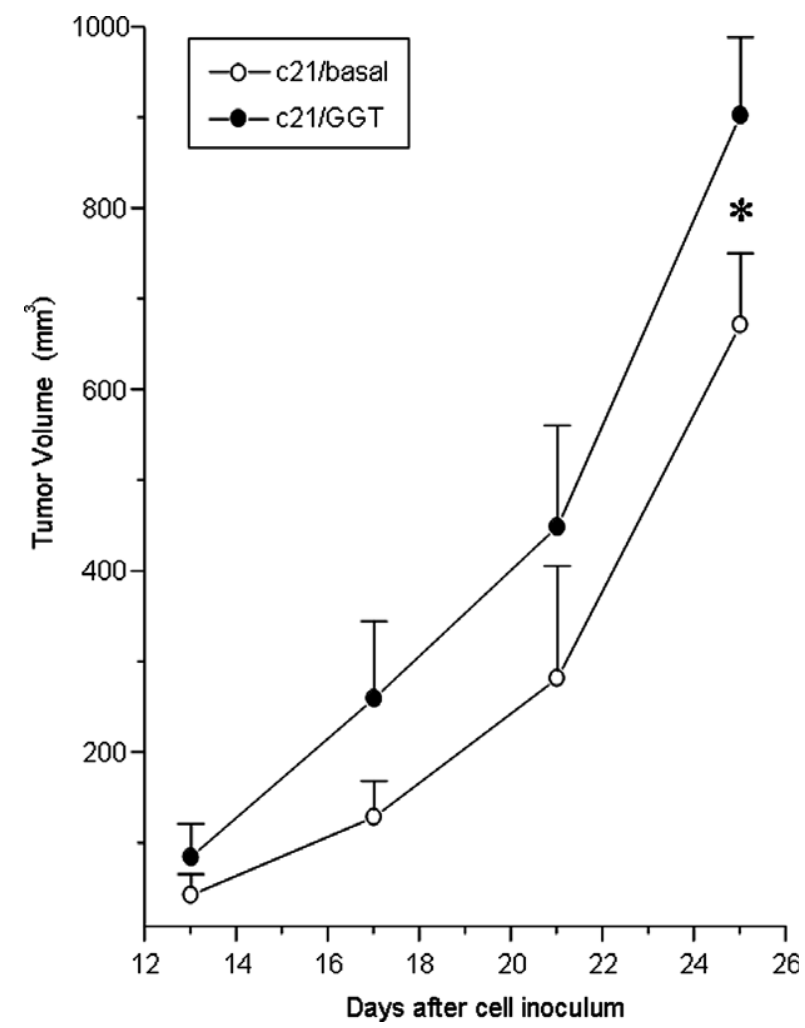

Fig. 2 - In vivo growth of human melanoma clones. Tumour cells $\left(9 \times 10^{6}\right)$ were injected s.c. in nude mice on the right flank; see Section 2 for further details. Data are means $( \pm S D)$ of six tumours. ${ }^{*} P<0.01$.

\begin{tabular}{|c|c|c|}
\hline & c21/basal & c21/GGT \\
\hline Wet weight (g) & $0.45 \pm 0.05$ & $0.80 \pm 0.02^{*}$ \\
\hline GSH (nmol/mg wet wt) & $5.38 \pm 0.79$ & $4.10 \pm 0.46^{*}$ \\
\hline
\end{tabular}

\subsection{DNA-bound Pt after cisplatin exposure}

Since DNA is recognised as the primary cellular target of cisplatin, we examined DNA-bound platinum in c21/GGT and c21/basal cells after $1 \mathrm{~h}$ drug exposure in standard RPMI 1640 medium. The amount of platination was reduced in c21/GGT cells, thereby suggesting that the observed decreased sensitivity of the cells with higher GGT activity reflects a reduced interaction of the drug with the intracellular target (Fig. 5).

\subsection{Dependence of intracellular glutathione levels on extra-} cellular cysteine and GSH levels

When cultured in standard RPMI 1640 medium, c21/GGT cells exhibited lower intracellular GSH and higher GSSG levels than c21/basal cells, even though the higher membrane GGT activity of c21/GGT cells was expected to favour the maintenance of intracellular GSH levels (Table 2).

Similar results were obtained in SAF-cultured cells. Intracellular GSH concentrations in c21/basal and c21/GGT clones were independent of GGT expression, and appeared to depend solely on extracellular cysteine. In $10 \mu \mathrm{M}$ cysteine-containing SAF, supplementation of medium with $30 \mu \mathrm{M}$ GSH allowed increased intracellular glutathione in both cell lines (Fig. 6), again suggesting that GGT activity was not involved in the modulation of intracellular GSH.

\subsection{GGT expression and extracellular low molecular weight thiols}

Low molecular weight thiols were determined in the culture supernatants of the two transfected clones. As reported in Table 3, high extracellular levels of GSH were present in the supernatant from c21/basal cells, along with very low cysteinyl-glycine. The situation was reversed with c21/GGT cells, exhibiting very low extracellular GSH and high cysteinyl-glycine levels, resulting from GGT-mediated catabolism of GSH. Extracellular cysteine levels were instead comparable in the two clones.

\section{Discussion}

The present study suggests that the relationships of GGT with cellular thiol metabolism and functions are more complex than those currently recognised. Overexpression of GGT provided human melanoma cells ${ }^{26}$ with increased growth capability, both in vitro (Fig. 1) and in vivo (Fig. 2, Table 1). However, the expression of GGT did not favour the intracellular supply of GSH; indeed, both xenotransplants and cultured 


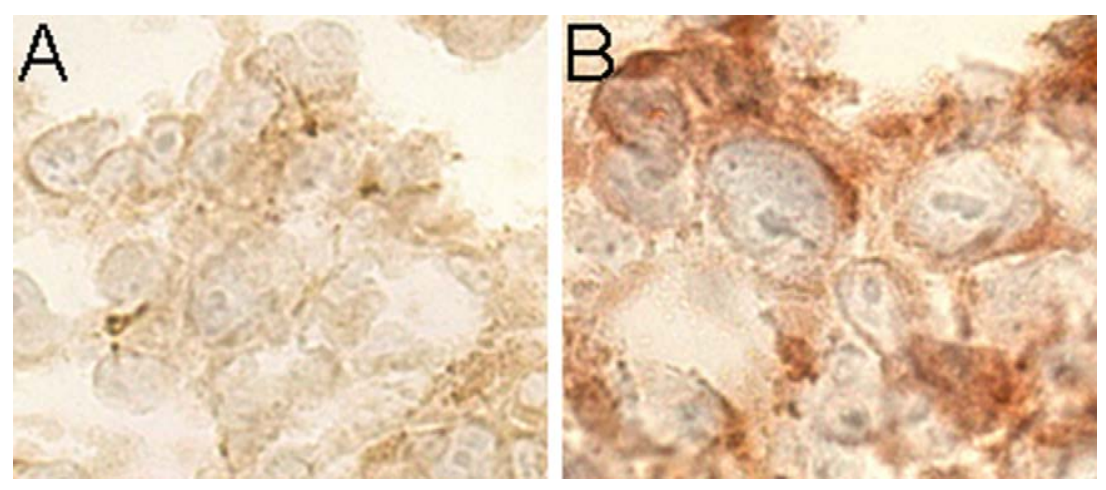

Fig. 3 - Histochemical staining for GGT enzyme activity (red) in frozen sections obtained from tumours grown in immunodeficient nude mice, produced by (A) c21/basal cells and (B) c21/GGT cells. Magnification: 400x. (For interpretation of the references to colour in this figure legend, the reader is referred to the Web version of this article.)

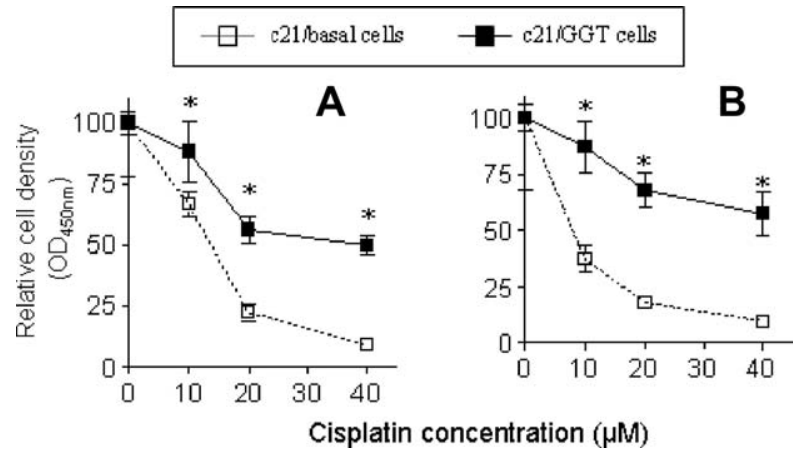

Fig. 4 - Cell sensitivity to CDDP. c21/basal ( $\square$ ) and c21/GGT ( $\square$ ) cells were seeded and grown for $24 \mathrm{~h}$ in standard RPMI 1640 medium, containing $400 \mu \mathrm{M}$ cysteine and 3.25 $\mu \mathrm{M}$ GSH (A), or in conditions of limiting cysteine availability (B; cysteine $10 \mu \mathrm{M}$, GSH $30 \mu \mathrm{M}$ ), before treating with the indicated concentrations of CDDP. Cells were incubated $24 \mathrm{~h}$ with CDDP and the number of live cells was measured thereafter using WST-1 assay. Results are expressed as \% of untreated controls, and are means \pm SD of 12-36 independent replications. " $P<0.001$.

cells presented significantly lower GSH levels after GGT transfection (Tables 1 and 2). These findings are in keeping with previous observations in different cell systems, including chemically transformed murine epidermal cells and human prostatic cancer cells. ${ }^{10,14}$

It has been proposed that the expression of GGT might provide tumour cells with a selective growth advantage at limiting cysteine concentrations. ${ }^{5}$ However, the results reported in the present study indicate that the expression of GGT is not accompanied by increased intracellular GSH supply, and therefore this parameter cannot explain the increased proliferation of GGT-transfected cells, both in vitro and in vivo.

GGT expression also induced CDDP resistance in transfected cells, which exhibited a higher IC $_{50}$ than c21/basal (Fig. 4A and B) and decreased levels of DNA platination (Fig. 5). The finding cannot however be explained by any increase of intracellular GSH (Tables 1 and 2); rather, the

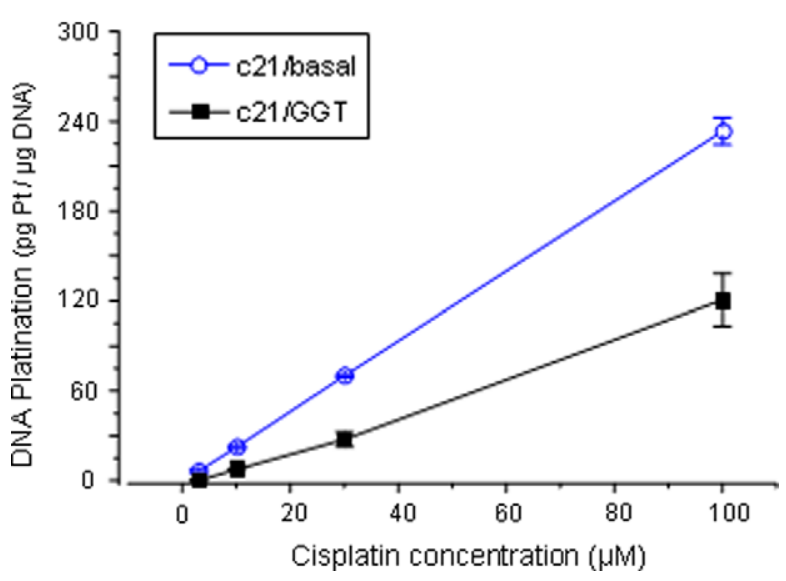

Fig. 5 - DNA-bound platinum in c21/basal as compared to c21/GGT cells. Cells were exposed to cisplatin for $1 \mathrm{~h}$. Platination was measured by inductively coupled plasma mass spectroscopy. Values shown are means \pm SD of three measurements.

Table 2 - Intracellular GSH and GSSG levels ${ }^{a}$

\begin{tabular}{|c|c|c|}
\hline nmol GSH eq./mg protein & c21/basal & c21/GGT \\
\hline Total (GSH + GSSG) & $74.74 \pm 2.11$ & $60.14 \pm 4.75^{*}$ \\
\hline GSSG & $0.26 \pm 0.09$ & $0.43 \pm 0.01^{* *}$ \\
\hline GSH (Total-GSSG) & $74.48 \pm 2.11$ & $59.71 \pm 4.75^{*}$ \\
\hline GSH/GSSG ratio & 286.46 & 138.86 \\
\hline \multicolumn{3}{|c|}{$\begin{array}{l}\text { Determinations were performed } 72 \mathrm{~h} \text { after plating cells in stan- } \\
\text { dard conditions. Data are means } \pm \mathrm{SD} \text { of } 3 \text { separate } \\
\text { determinations. } \\
{ }^{*} \mathrm{P}<0.01 \text {. } \\
* \mathrm{P}<0.05 \text {. }\end{array}$} \\
\hline
\end{tabular}

higher CDDP resistance of c21/GGT cells is likely due to the reactivity of cysteinyl-glycine, produced by GGT-mediated GSH catabolism (Table 3). We have in fact previously shown that cysteinyl-glycine is considerably more reactive than GSH in forming complexes with CDDP, ${ }^{18,19}$ and that GGTexpressing cells are in this way capable of promoting the 


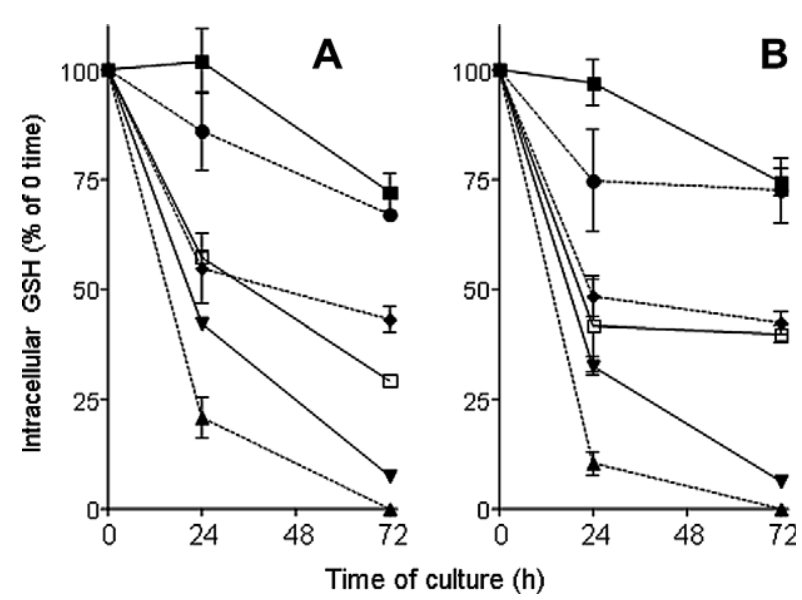

Fig. 6 - Dependence of intracellular glutathione levels of c21/ basal (A) and c21/GGT (B) cells on extracellular cysteine and GSH. After $24 \mathrm{~h}$ of culture, standard RPMI 1640 medium was replaced with SAF medium, containing $3 \mu \mathrm{M}$ GSH and supplemented with the following cysteine concentrations $(\mu \mathrm{M})$ : 0 (A); $10(\nabla) ; 30(\Delta) ; 200(0) ; 400(\square)$. Additional incubations were performed in SAF medium containing $10 \mu \mathrm{M}$ cysteine and $30 \mu \mathrm{M}$ GSH together $(\square)$. Intracellular concentration of GSH was measured at the indicated time points and expressed as percentage of time 0 . Data shown are means \pm SD of three separate determinations.

Table 3 - Extracellular accumulation of low molecular weight thiols in the supernatant of melanoma clones ${ }^{a}$

\begin{tabular}{lcc}
$\mu \mathrm{M}$ & $\mathrm{C} 21 /$ basal & c21/GGT \\
\hline GSH & $4.69 \pm 0.48$ & $0.47 \pm 0.11^{*}$ \\
CysGly & $0.15 \pm 0.05$ & $6.17 \pm 0.19^{* *}$ \\
Cys & $6.15 \pm 1.20$ & $7.66 \pm 0.60$ \\
\hline
\end{tabular}

${ }^{\mathrm{a}}$ Low molecular weight thiols were assayed after $24 \mathrm{~h}$ cell culture in SAF medium. Data are means \pm SD of 3 separate determinations. $* P<0.01$.

** $P<0.001$.

extracellular formation of CDDP complexes. The decreased DNA platination suggests a decreased intracellular accumulation of CDDP or a decreased reactivity of CDDP/thiol complexes with intracellular targets. The difference in CDDP resistance was more evident when cells were treated in the presence of low cysteine $(10 \mu \mathrm{M})$ and high $\mathrm{GSH}(30 \mu \mathrm{M})$ concentrations (Fig. 4B). Under these conditions in fact, deprivation of thiol precursors for GSH resynthesis only affects the resistance of c21/basal cells, which rely for their defences solely on intracellular GSH stores. On the contrary, c21/GGT cells, being able to metabolise exogenous GSH, can take advantage of the protection provided by the extracellular cysteinyl-glycine thus formed.

A favouring role of GGT activity in cellular supply of GSH could not be found even in the presence of limiting cysteine concentrations (Fig. 6). Under these conditions, the expression of GGT did not allow the maintenance of intracellular GSH; the latter instead decreased in time, with comparable rates in c21/basal and c21/GGT. In both clones, depletion of intracellular GSH was, however, delayed in the presence of exogenously added GSH $(30 \mu \mathrm{M})$. This effect can be explained as the result of the reducing action of GSH on the extracellular redox status; ${ }^{27}$ reducing conditions were shown to favour the cellular uptake of cysteine/cystine. In different cell types, membrane transport of cysteine is more efficient than that of cystine, ${ }^{28,29}$ and thus extracellular reducing agents like $\mathrm{N}$ acetylcysteine, ${ }^{29,30}$ cysteinyl-glycine ${ }^{29}$ and GSH itself ${ }^{29,31}$ can favour the cellular thiol supply by reducing the extracellular cystine to more rapidly absorbed cysteine. Cystine is present in standard RPMI 1640 medium, and accumulates extracellularly with both cell lines studied - likely as the result of cellular secretion and subsequent autoxidation of cysteine (Table 3). ${ }^{16}$ At least with c21/GGT cells, the reduction of cystine might in principle be affected by cysteinyl-glycine, which indeed accumulates extracellularly as the result of GGT activity. However, c21/GGT cells did not transport more cystine than c21/basal cells (Table 3), likely because the amount of cysteinyl-glycine formed (approximately $6 \mu \mathrm{M}$, cf. Table 3 ) is too low. In fact, higher levels of reducing thiols are needed for producing significant effects ${ }^{29}(30-60 \mu \mathrm{M})$.

Both growth rate and resistance to CDDP appeared to be independent of GSH as a secondary source of cysteine, thus indicating that the important effects caused by GGT activity are unrelated to cellular supply of GSH thiol precursors. Previous studies carried out in our and other laboratories have shown that GGT activity can participate in redox processes taking place in the extracellular microenvironment. ${ }^{32-36}$ In fact, cysteinyl-glycine released after GSH hydrolysis was shown to catalyse the extracellular production of reactive oxygen species, including hydrogen peroxide. ${ }^{32,33}$ Through the action of these reactive compounds, GGT activity can give rise to cytotoxic injuries. ${ }^{34-36}$ In contrast, more subtle and physiological changes have been described, such as the oxidation/S-thiolation of thiol groups of cellular proteins. ${ }^{16,32,37}$ Modulating, rather than injuring, effects have been observed on several redox-sensitive components of signal transduction chains, such as the transcriptions factors $\mathrm{NF}-\kappa \mathrm{B}$ and AP-1 ${ }^{33,38,39}$ and protein tyrosine or serine/threonine kinase/phosphatase balance. ${ }^{40}$ Oxidative changes produced by GGT activity may activate redox-sensitive and protective pathways enabling cells to survive under stress conditions. Moreover, pro-oxidant effects of GGT were also described for elements involved in the proliferation/apoptotic balance, such as poly(ADP-ribose) polymerase activity and the cell surface receptor TNFR-1. ${ }^{12,41}$ Altogether, such modulatory changes might well account for the changes in cellular growth rates induced after GGT transfection in the present study, as well as for the previously shown involvement of GGT in mediating GSH-dependent antiproliferative effects in ovarian carcinoma cells. ${ }^{42}$

In conclusion, the present findings indicate that GGT expression in melanoma cells results in growth advantage in vitro and in vivo, as well as in increased CDDP-resistance. Neither effect can be attributed to facilitating effects of GGT on the cellular supply of cysteine or glutathione. Rather, CDDP resistance is likely the consequence of cellular pharmacokinetics as a result of extracellular drug inactivation by thiol metabolites originated from GGT-mediated GSH cleavage. 


\section{Conflict of interest statement}

None declared.

\section{Acknowledgements}

The present study was supported by the Italian Ministry for Education, University and Research (MIUR-PRIN and FIRB funds). Additional funds were derived from AIRC (Associazione Italiana Ricerca sul Cancro, Milan, Italy).

\section{R E F E R E N C E S}

1. Tate SS, Meister A. Gamma-glutamyl transpeptidase: catalytic, structural and functional aspects. Mol Cell Biochem 1981;39:357-68.

2. Hanigan MH, Frierson Jr HF, Swanson PE, De Young BR. Altered expression of gamma-glutamyl transpeptidase in human tumors. Hum Pathol 1999;30:300-5.

3. Tew KD, Monks A, Barone L, et al. Glutathione-associated enzymes in the human cell lines of the National Cancer Institute Drug Screening Program. Mol Pharmacol 1996;50:149-59.

4. Lu SC. Regulation of hepatic glutathione synthesis: current concepts and controversies. FASEB J 1999;13:1169-83.

5. Hanigan MH. Expression of gamma-glutamyl transpeptidase provides tumor cells with a selective growth advantage at physiologic concentrations of cyst(e)ine. Carcinogenesis 1995;16:181-5.

6. Rajpert-De Meyts E, Shi M, Chang M, et al. Transfection with gamma-glutamyl transpeptidase enhances recovery from glutathione depletion using extracellular glutathione. Toxicol Appl Pharmacol 1992;114:56-62.

7. Hanigan MH, Ricketts WA. Extracellular glutathione is a source of cysteine for cells that express gamma-glutamyl transpeptidase. Biochemistry 1993;32:6302-6.

8. Godwin AK, Meister A, O'Dwyer PJ, et al. High resistance to cisplatin in human ovarian cancer cell lines is associated with marked increase of glutathione synthesis. Proc Natl Acad Sci USA 1992;89:3070-4.

9. Hromas RA, Andrews PA, Murphy MP, Burns CP. Glutathione depletion reverses cisplatin resistance in murine L1210 leukemia cells. Cancer Lett 1987;34:9-13.

10. Hanigan MH, Gallagher BC, Townsend DM, Gabarra V. Gamma-glutamyl transpeptidase accelerates tumor growth and increases the resistance of tumors to cisplatin in vivo. Carcinogenesis 1999;20:553-9.

11. Bailey HH, Gipp JJ, Mulcahy RT. Increased expression of gamma-glutamyl transpeptidase in transfected tumor cells and its relationship to drug sensitivity. Cancer Lett 1994;87:163-70.

12. Del Bello B, Paolicchi A, Comporti M, Pompella A, Maellaro E. Hydrogen peroxide produced during gamma-glutamyl transpeptidase activity is involved in prevention of apoptosis and maintenance of proliferation in U937 cells. FASEB J 1999;13:69-79.

13. Karp DR, Shimooku K, Lipsky PE. Expression of gammaglutamyl transpeptidase protects ramos B cells from oxidation-induced cell death. J Biol Chem 2001;276:3798-804.

14. Warren BS, Naylor MF, Winberg LD, et al. Induction and inhibition of tumor progression. Proc Soc Exp Biol Med 1993;202:9-15.
15. Manzotti C, Pratesi G, Menta E, et al. BBR3464: a novel triplatinum complex, exhibiting a preclinical profile of antitumor efficacy different from cisplatin. Clin Cancer Res 2000;6:2626-34.

16. Paolicchi A, Lorenzini E, Perego P, et al. Extra-cellular thiol metabolism in clones of human metastatic melanoma with different gamma-glutamyl transpeptidase expression: implications for cell response to platinum-based drugs. Int $J$ Cancer 2002;97:740-5.

17. Dominici S, Paolicchi A, Lorenzini E, et al. Gammaglutamyltransferase-dependent prooxidant reactions: a factor in multiple processes. Biofactors 2003;17:187-98.

18. Daubeuf S, Leroy P, Paolicchi A, et al. Enhanced resistance of HeLa cells to cisplatin by overexpression of gammaglutamyltransferase. Biochem Pharmacol 2002;64:207-16.

19. Paolicchi A, Sotiropuolou M, Perego P, et al. Gamma-glutamyl transpeptidase catalyses the extracellular detoxification of cisplatin in a human cell line derived from the proximal convoluted tubule of the kidney. Eur J Cancer 2003;39:996-1003.

20. Courtay C, Oster T, Michelet F, et al. Gammaglutamyltransferase: nucleotide sequence of the human pancreatic cDNA. Evidence for a ubiquitous gammaglutamyltransferase polypeptide in human tissues. Biochem Pharmacol 1992;43:2527-33.

21. Huseby NE, Stromme JH. Practical points regarding routine determination of gamma-glutamyl transferase (gamma-GT) in serum with a kinetic method at $37^{\circ} \mathrm{C}$. Scand J Clin Lab Invest 1974;34:357-63.

22. Baker MA, Cerniglia GJ, Zaman A. Microtiter plate assay for the measurement of glutathione and glutathione disulfide in large numbers of biological samples. Anal Biochem 1990;190:360-5.

23. Pfeiffer CM, Huff DL, Gunter EW. Rapid and accurate HPLC assay for plasma total homocysteine and cysteine in a clinical laboratory setting. Clin Chem 1999;45:290-2.

24. Perego P, Caserini C, Gatti L, et al. A novel trinuclear platinum complex overcomes cisplatin resistance in an osteosarcoma cell system. Mol Pharmacol 1999;55:528-34.

25. Bradford MM. A rapid and sensitive method for the quantitation of microgram quantities of protein utilizing the principle of protein-dye binding. Anal Biochem 1976;72:248-54.

26. Supino R, Mapelli E, Sanfilippo O, Silvestro L. Biological and enzymatic features of human melanoma clones with different invasive potential. Melanoma Res 1992;2:377-84.

27. van Klaveren RJ, Demedts M, Nemery B. Cellular glutathione turnover in vitro, with emphasis on type II pneumocytes. Eur Respir 1997;10:1392-400.

28. Bannai S, Tateishi N. Role of membrane transport in metabolism and function of glutathione in mammals. $J$ Membr Biol 1986;89:1-8.

29. Knickelbein RG, Seres T, Lam G, Johnston Jr RB, Warshaw JB. Characterization of multiple cysteine and cystine transporters in rat alveolar type II cells. Am J Physiol 1997;273:L1147-55.

30. Phelps DT, Deneke SM, Daley DL, Fanburg BL. Elevation of glutathione levels in bovine pulmonary artery endothelial cells by N-acetylcystine. Am J Respir Cell Mol Biol 1992;7:293-9.

31. Deneke SM, Susanto I, Vogel KA, Williams CE, Lawrence RA. Mechanisms of use of extracellular glutathione by lung epithelial cells and pulmonary artery endothelial cells. Am J Respir Cell Mol Biol 1995;12:662-8.

32. Dominici S, Valentini M, Maellaro E, et al. Redox modulation of cell surface protein thiols in U937 lymphoma cells: the role of gamma-glutamyl transpeptidase-dependent $\mathrm{H}_{2} \mathrm{O}_{2}$ production and S-thiolation. Free Rad Biol Med 1999;27:623-35.

33. Maellaro E, Dominici S, Del Bello B, et al. Membrane gamma-glutamyl transpeptidase activity of melanoma cells: 
effects on cellular $\mathrm{H}(2) \mathrm{O}(2)$ production, cell surface protein thiol oxidation and NF-kappa B activation status. J Cell Sci 2000;113:2671-8.

34. Stark AA, Zeiger E, Pagano DA. Glutathione metabolism by gamma-glutamyltranspeptidase leads to lipid peroxidation: characterization of the system and relevance to hepatocarcinogenesis. Carcinogenesis 1993;14:183-9.

35. Paolicchi A, Tongiani R, Tonarelli P, Comporti M, Pompella A. Gamma-glutamyl transpeptidase-dependent lipid peroxidation in isolated hepatocytes and HepG2 hepatoma cells. Free Rad Biol Med 1997;22:853-60.

36. Paolicchi A, Minotti G, Tonarelli P, et al. Gamma-glutamyl transpeptidase-dependent iron reduction and LDL oxidation a potential mechanism in atherosclerosis. J Investig Med 1999;47:151-60.

37. Corti A, Paolicchi A, Franzini M, et al. The S-thiolating activity of membrane $\gamma$-glutamyltransferase: formation of cysteinyl-glycine mixed disulfides with cellular proteins and in the cell microenvironment. Antiox Redox Signall 2005;7:911-8.
38. Dominici S, Visvikis A, Pieri L, et al. Redox modulation of NF- $\kappa$ B nuclear translocation and DNA binding in metastatic melanoma - the role of endogenous and gammaglutamyltransferase-dependent oxidative stress. Tumori 2003;89:428-35.

39. Paolicchi A, Dominici S, Pieri L, Maellaro E, Pompella A. Glutathione catabolism as a signaling mechanism. Biochem Pharmacol 2002;64:1027-35.

40. Pieri L, Dominici S, Del Bello B, et al. Redox modulation of protein kinase/phosphatase balance in melanoma cells: the role of endogenous and gamma-glutamyltransferasedependent $\mathrm{H}_{2} \mathrm{O}_{2}$ production. Biochim Biophys Acta 2003;1621:76-83.

41. Dominici S, Pieri L, Paolicchi A, et al. Endogenous oxidative stress induces distinct redox forms of tumor necrosis factor receptor-1 in melanoma cells. Ann NY Acad Sci 2004;1030:62-8.

42. Perego P, Paolicchi A, Tongiani R, et al. The cell-specific anti-proliferative effect of reduced glutathione is mediated by gamma-glutamyl transpeptidase-dependent extracellular pro-oxidant reactions. Int J Cancer 1997;71:246-50. 